\title{
A new species of Panopsis (Proteaceae) from Bahia, Brazil
}

\author{
Ghillean T. Prance
}

Royal Botanic Gardens, Kew, Richmond, Surrey, TW9 3AB, UK; e-mail: siriain01@yahoo.co.uk

\begin{abstract}
Recent collections from Bahia, Brazil included a new species of Panopsis from the Atlantic rainforest. So far it is only known with fruits, which are much larger than in most species of the genus. Panopsis magnifructa is described and compared to other species in the genus. It is only the second species of the genus known in the State of Bahia, Brazil.
\end{abstract}

Keywords: Proteaceae, Panopsis, mata Atlántica, Bahia.

Panopsis Salisb. ex Knight is a genus of 25 species endemic to Central and South America. In Brazil it is represented by three species, P. sessilifolia (Rich.) Sandwith, P. rubescens (Pohl) Rusby and P. multiflora (Schott) Ducke. The latter species is endemic to southeast Brazil but is not known in the State of Bahia. Recent collections from Bahia include a new species of Panopsis, to add to the 25 species described in the monograph of Neotropical Proteaceae in Flora Neotropica (Prance et al., 2007). This new species is notable for its large globose fruit, only surpassed in the genus by P. macrocarpa K. S. Edwards \& R. T. Pennington from Panama. It is only the second species of Panopsis recorded from Bahia. The other, P. rubescens (Pohl) Rusby is very different and is unlikely to be closely related to $P$. magnifructa.

\section{Species description}

Panopsis magnifructa Prance, sp. nov. Type: Brazil. Bahia: Mata da Esperança, west part, Road Ilhéus-Itabuna, Banco da Vitória, $14^{\circ} 46^{\prime}$ $30^{\prime \prime} \mathrm{S}, 39^{\circ} 05^{\prime} 00^{\prime \prime} \mathrm{W}, 30$ Jan 2000 (fr), J. G. Jardin et al. 2594 (holotype: CEPEC; isotypes: K, NY) (Figs. 1 and 2).

Diagnosis: Among the species of Panopsis, $P$. magnifructa is similar to $P$. macrocarpa in the large fruits, but differs in the smaller leaves $(10$ $17 \times 4-8 \mathrm{~cm}$ vs. $17-26 \times 8.5-18 \mathrm{~cm})$ the cuneate rather than cordate leaf base and the smaller fruit with only a slightly mammiliform apex $(5-6.5 \mathrm{~cm}$ vs. $8-9 \mathrm{~cm})$.

Tree 6-15 $\mathrm{m}$ tall, the young branches glabrous, lenticellate, the lenticels sparse, protruding $0.5-1$ $\mathrm{mm}$. Leaves without stipules, alternate to spiral; petioles 5-14 mm long, glabrous, terete, slightly swollen at base: lamina thickly coriaceous, 10 $17 \times 4-8 \mathrm{~cm}$, oblong, cuneate at base, rounded or obtuse at apex, glabrous; margin entire, slightly revolute; primary veins 9-13 pairs, emerging from midrib at $70^{\circ}$, brochidodromous, prominulous on both surfaces, anastomosing $5-10 \mathrm{~mm}$ from margin; tertiary veins finely reticulate, prominulous and conspicuous; midrib prominent beneath, plane to slightly submerged above. Inflorescence and flowers not seen. Fruit globose, apex smooth or slightly mammiliform, $5-6.5 \mathrm{~cm}$ diameter; pericarp 4-5 mm thick, hard and woody, exterior smooth with prominent lenticels abundant; interior endocarp thin, shiny within, glabrous; seed coat fused to pericarp.

Field notes.-Leaf nerves yellow, fruits ridged and greenish with a smooth exterior.

Distribution and ecology.-Atlantic rainforests in Bahia, known from only two collections.

Phenology.-Collected in fruit in January and in June.

Additional specimen examined. BRAZIL. Bahia: Municipio de Conde, Rodovia BA-099, km 127, Mata do Bu, $12^{\circ} 01^{\prime} 21^{\prime \prime} \mathrm{S}, 37^{\circ} 41^{\prime} 35^{\prime \prime} \mathrm{W}, 50-100 \mathrm{~m}$ elev., 14 June 2000 (fr), M. Alves 2022 (CEPEC, NY). 


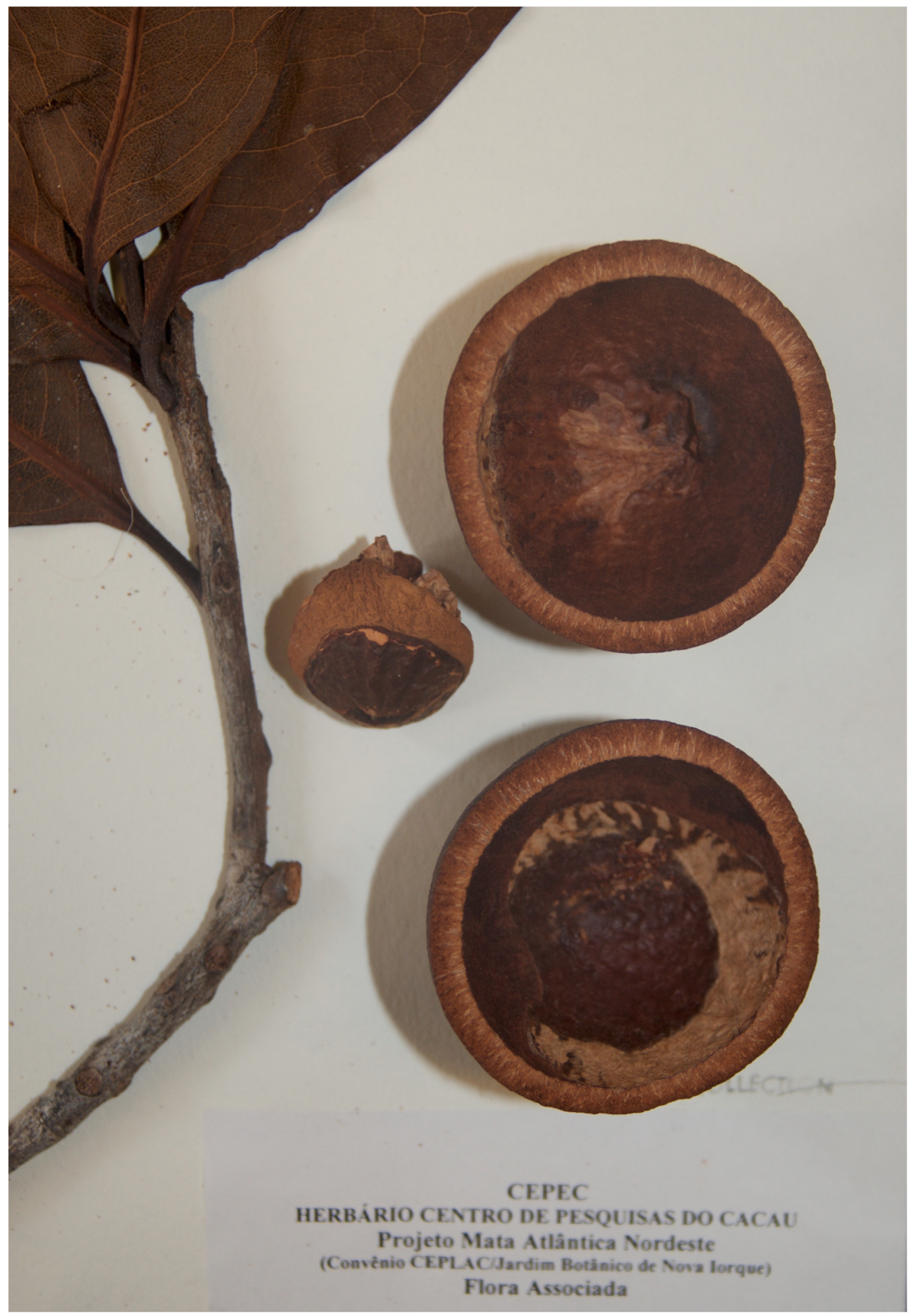

Fig. 1. Photo of the paratype of Panopsis magnifructa, M. Alves 2022 (NY) 

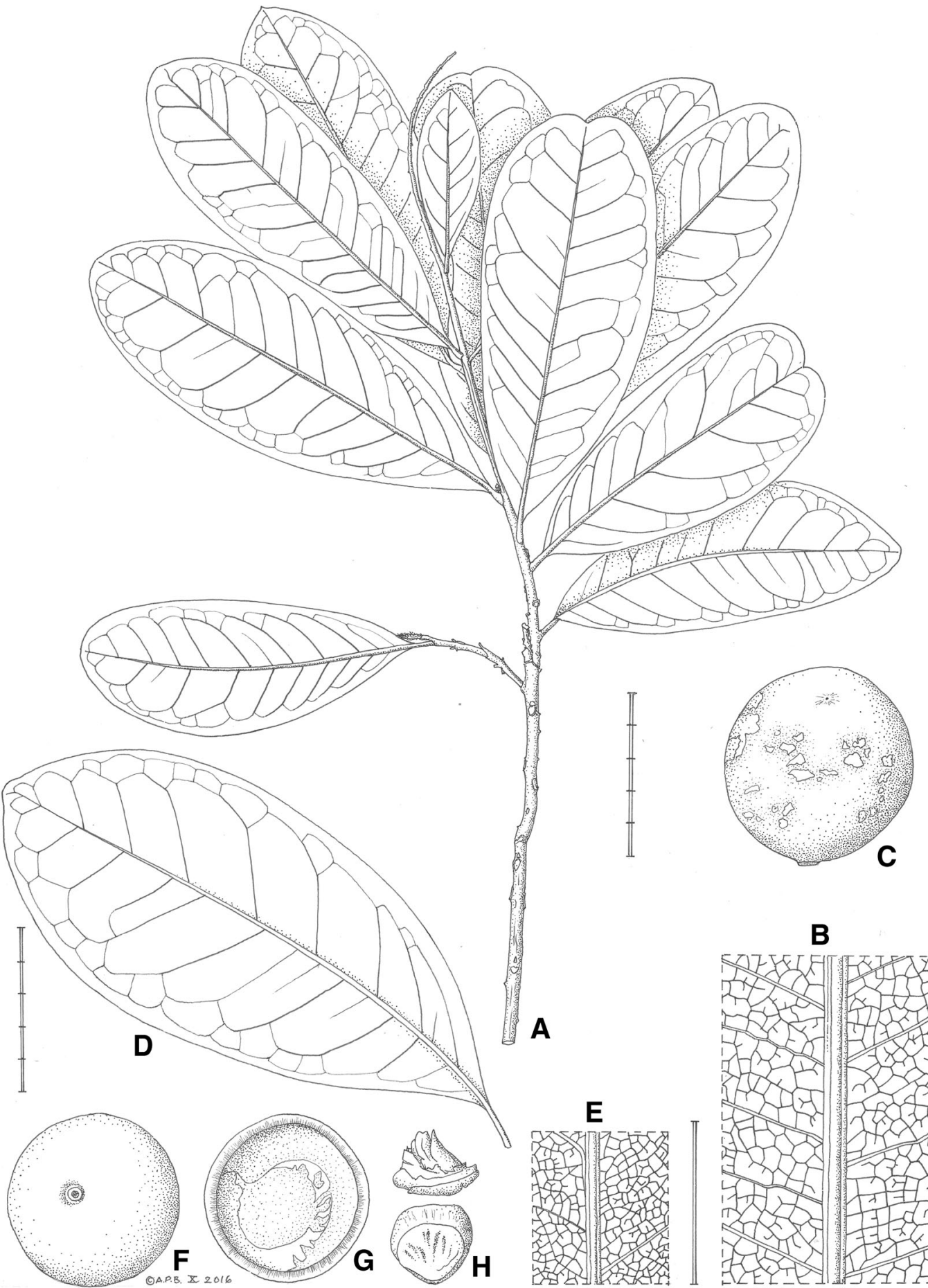

A

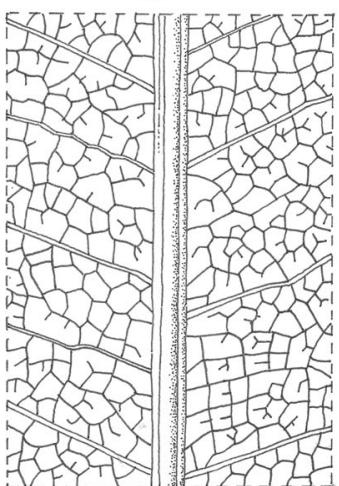

Fig. 2. Drawing of Panopsis magnifructa. A. Habit. B. Leaf abaxial surface showing dense reticulate venation. C. Lateral view of fruit. D. Largest leaf from Jardin et al. 2594. E. Leaf abaxial surface showing dense reticulate venation. F. Ventral view of fruit. G. Fruit section to show ventral surface and seed attachment. H. Two views of seed. (A-C from Alves 2022; D-H from Jardin et al. 2594; drawn by Andrew Brown; scales: double bar $=1 \mathrm{~cm}$, graduated bar $=5 \mathrm{~cm}$ ) 
This species is quite distinct from any in the genus recorded in Bahia or nearby. So far it has only been collected with mature fruit, but both the fruit and the leaves, with their characteristic prominulous venation, clearly place it in the genus Panopsis. Panopsis magnifructa is probably closest to P. multiflora (Schott) Ducke from the Planalto of Central Brazil and forests around Rio de Janeiro with which it shares the blunt leaf apex and the round fruit. It differs in the larger much more coriaceous leaves, the larger fruit $(3 \mathrm{~cm}$ diam. vs $5-6.5 \mathrm{~cm}$ ) and the glabrous vegetative parts. It differs from $P$. sessiliflora by the glabrous vegetative parts and the large fruit. The only species of Panopsis with a fruit of this size is P. macrocarpa K. S. Edwards \& R. T. Pennington from Panama. The only other species of Panopsis recorded from Bahia is $P$. rubescens (Pohl) Rusby, which differs in many ways in both the larger chartaceous leaves and the ellipsoid small fruit that is pubescent when young.

\section{Acknowledgments}

I thank Jackie Kallunki for bringing this new species to my attention and Andrew Brown for drawing the illustration.

Open access This article is distributed under the terms of the Creative Commons Attribution 4.0 International License ( http:// creativecommons.org/licenses/by/4.0/), which permits unrestricted use, distribution, and reproduction in any medium, provided you give appropriate credit to the original author(s) and the source, provide a link to the Creative Commons license, and indicate if changes were made.

\section{Literature cited}

Prance, G.T., V. Plana, K. S. Edwards \& R. T. Pennington. 2007. Proteaceae. Flora Neotropica Monograph 100: 1218. 